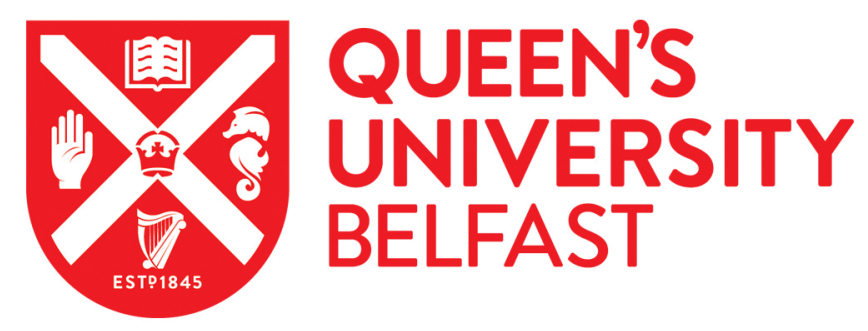

\title{
Influence of primary care antibiotic prescribing on incidence rates of multidrug-resistant Gram-negative bacteria in hospitalised patients
}

Alnajjar, M. S., Aldeyab, M. A., Scott, M. G., Kearney, M. P., Fleming, G., Glimore, F., Farren, D., \& McElnay, J. C. (2019). Influence of primary care antibiotic prescribing on incidence rates of multidrug-resistant Gramnegative bacteria in hospitalised patients. Infection. https://doi.org/10.1007/s15010-019-01305-6

\section{Published in:}

Infection

\section{Document Version:}

Peer reviewed version

Queen's University Belfast - Research Portal:

Link to publication record in Queen's University Belfast Research Portal

Publisher rights

(C) 2019 Springer-Verlag GmbH Germany, part of Springer Nature.

This work is made available online in accordance with the publisher's policies. Please refer to any applicable terms of use of the publisher.

\section{General rights}

Copyright for the publications made accessible via the Queen's University Belfast Research Portal is retained by the author(s) and / or other copyright owners and it is a condition of accessing these publications that users recognise and abide by the legal requirements associated with these rights.

Take down policy

The Research Portal is Queen's institutional repository that provides access to Queen's research output. Every effort has been made to ensure that content in the Research Portal does not infringe any person's rights, or applicable UK laws. If you discover content in the Research Portal that you believe breaches copyright or violates any law, please contact openaccess@qub.ac.uk. 
1 Influence of primary care antibiotic prescribing on incidence rates of multidrug2 resistant Gram-negative bacteria in hospitalised patients

3 Munther S. Alnajjar ${ }^{1,2}$. Mamoon A. Aldeyab ${ }^{3}$. Michael G. Scott ${ }^{4}$. Mary Kearney ${ }^{5}$. Glenda Fleming ${ }^{4}$.

$4 \quad$ Fiona Glimore $^{4}$. David Farren ${ }^{5}$. James C. McElnay ${ }^{1 *}$

$5 \quad{ }^{1}$ Clinical and Practice Research Group, School of Pharmacy, Queen's University Belfast, BT9 7BL

6 Belfast, Northern Ireland, UK

$7 \quad{ }^{2}$ Department of Clinical Pharmacy, College of Pharmacy, Al Ain University of Science \& Technology,

8 Al Ain, United Arab Emirates

$9 \quad{ }^{3}$ School of Pharmacy and Pharmaceutical Sciences, Coleraine, Ulster University, UK

$10{ }^{4}$ Medicines Optimisation Innovation Centre, Trust Headquarters Brettan Hall, Antrim Area Hospital 11 BT41 2RL, Northern Ireland, UK

$12{ }^{5}$ Area Microbiology Laboratory Antrim Area Hospital Antrim BT41 2RL, Northern Health and Social 13 Care Trust, Northern Ireland, UK

$14 *$ Corresponding author:

15 Professor James C. McElnay

16 Professor of Pharmacy Practice

17 School of Pharmacy

18 Queen's University Belfast

19 Belfast BT7 1NN

20 Tel: +44-28-90975802; Fax: +44-28-90434454; E-mail: j.mcelnay@qub.ac.uk 


\section{Abstract:}

32

\section{Conclusion:}

\section{Purpose:}

\section{Methods:}

\section{$\underline{\text { Results: }}$}

Use of antibiotics can give rise to the selection of resistant bacteria. It remains unclear whether antibiotic use in primary care can influence bacterial resistance incidence in patients when hospitalized. The aim of this study is to explore the impact of prior community antibiotic usage on hospital detected multidrugresistant gram-negative (MRGN) incidence rate.

This pharmacoepidemiological study was case-control in design, and was carried out in the Antrim Area Hospital (N. Ireland) in two phases. In phase 1, the controls were matched according to: age, gender, admission ward, date of admission and age-adjusted Charlson co-morbidity index score. During the second phase, controls were selected randomly from the total population of admissions to the hospital over the 2-year study period.

In phase 1, multivariate analysis revealed that prior exposure to second and third generation cephalosporins $(\mathrm{p}=0.004)$ and fluoroquinolones $(\mathrm{p}=0.023)$ in primary care was associated with an increased likelihood of MRGN detection in inpatients. In phase 2, an independent relationship between an increased risk of identification of MRGN while hospitalised was associated with: prolonged hospitalisation $(\mathrm{p}<0.001)$, being elderly $(\mathrm{p}<0.001)$, being female $(\mathrm{p}=0.007)$ and having genitourinary disease $(\mathrm{p}<0.001)$.

1 This study provides clear evidence which supports the need to optimise antibiotic use in primary care to help reduce MGRN incidence in hospitalised patients. 
53 Keywords: Primary care, Antibiotic prescribing, Multidrug-resistant Gram-negative bacteria (MRGN),

54 Hospitalised Patients, Antibiotic resistance, Pharmacoepidemiology

55

56

57

58

59

60

61

62

63

64

65

66

67

68

69 
Klebsiella pneumoniae and Escherichia coli represent the two main extended-spectrum $\beta$-lactamase (ESBL)-producing bacteria; they are listed as multidrug-resistant gram-negative (MRGN) bacteria for which new treatment regimens are urgently required [1]. Extended spectrum $\beta$-lactamases are a group of $\beta$-lactamase enzymes which hydrolyse and inactivate several types of $\beta$-lactam antibiotics [including expanded-spectrum (second and third generation) cephalosporins and monobactams] [1-4]. High antibiotic consumption is a well-established risk factor associated with the acquisition of Clostridium difficile infection (CDI), meticillin-resistant Staphylococcus aureus (MRSA) and MRGN bacteria [5, 6]. Many studies have demonstrated that infection with MRGN bacteria is associated with an increased rate of morbidity and mortality together with other measures of clinical failure including: longer hospital stay and/or increased antibiotic consumption within the hospital and community settings [2-6, 7-11]. Since the late 1990s, multidrug-resistant CTX-M-producing Escherichia coli have been detected within the primary healthcare setting as a leading cause of urinary tract infections and community-onset bacteraemia $[7,12-14]$. Few investigations have been performed to determine the impact of fluoroquinolone use within the community setting on the resistance level in fluoroquinoloneresistant Escherichia coli. Cooper et al. (2004) stated that the separation of primary and secondary healthcare settings, when linking antibiotic resistance to antibiotic use, is artificial, as the antibiotic resistance reservoir can be spread to hospitals from the surrounding primary care community and vice versa [15]. It has been proposed by Gallini et al. (2010) that studies with ecological (population) designs have significant value in evaluating the link between, fluoroquinolone use and FQ-R Escherichia coli, as such studies consider the ecological nature of the problem of antibiotic resistance [16]. Nevertheless, these authors suggested that such studies may have some limitations, indicating the need for conducting studies at both the population level and the individual patient level. In an earlier paper, Lopez-Lozano et al. (2000) emphasised that ecologic-level studies could be used to propose future interventions, but that individual patient level designs allow patient factors (e.g. patient demographics) to be taken into account [17]. Overall, there is a general view within the literature that there is the need for conducting studies at both the population level and the individual patient level to better understand the relationship between antibiotic use and resistance development. The influence of primary care antibiotic prescription on MRGN incidence rates in hospitalised patients (within the hospital which is the focus of the present study, i.e. the Antrim Area Hospital), was investigated in a 
101 recently published ecologic-level study [18]. The present work is a complementary study with the goal

102 of evaluating the impact of community antibiotic prescribing at the individual patient level on MRGN

103 bacteria detected in hospital.

104 Aim of the study

105 The aim of the investigation presented in this paper was to assess the impact of antibiotic prescribing,

106 during the previous 3, 6 and 12 months, in the community served by a medium sized hospital in N.

107 Ireland (Antrim Area Hospital; 426 beds) on the identification of MRGN bacteria in patients within the 108 study site hospital.

109

110

111

112

113

\section{Setting and study period}

The study was carried out in the Antrim Area Hospital (AAH) and its surrounding geographical community. Data required for the purposes of this study covered the period January 2012 to December 2013.

\section{Case definitions}

A multidrug-resistant gram-negative bacteria case was identified as a patient in whom a 3MRGN strain of bacteria (i.e. resistant to three of the four groups listed below) was recovered and identified, during their in-patient stay within the AAH between January 2012 and December 2013. Only 3MRGN isolates from any clinical samples were included. These isolates included both infection and colonization with 3MRGN bacteria. The classification of detected 3MRGN bacteria is based on pathogen susceptibility to the most important antibiotic groups [acylureidopenicillins, $3^{\text {rd }}$ and $4^{\text {th }}$ generation cephalosporins, carabapenems and fluoroquinolones; 19]. 
125 To estimate the Charlson co-morbidity index score in the present study, the ICD-10 coding system for 126 diseases was employed [20]. An age-adjusted co-morbidity index score was calculated for all the 127 patients involved in the research, by applying one additional point for each decade over 40 years of age 128 to the original index score $[20,21]$.

\section{Study design}

130 In order to identify particular antibiotics that were associated with hospital detected MRGN and to 131 identify risk factors for identification of MRGN organisms from clinical samples, two separate phases of research were implemented involving matching cases to two separate control groups.

133 Phase 1: Comparisons were made between case patients (i.e. identified as MRGN-positive patients) and a matched control group (two control patients for each case patient). The control group in this phase included patients with no positive result for MRGN, matched to case patients according to age (two categories: $16-65$ years and $>65$ ), gender, admission ward, date of admission ( \pm 30 days) and ageadjusted Charlson co-morbidity index score (two categories: 0-2 and $>2$ ).

138 Phase 2: In order to determine other risk factors for hospital detected MRGN pathogens (in particular 139 those used as matching criteria in phase 1) the cases were compared with a second control group (two 140 control patients for each case patient). The second control group included patients chosen randomly 141 [i.e. randomisation was achieved using computer software to generate random numbers] [22] from the 142 pool of patients who had no positive result for MRGN and who were admitted to the AAH over the two year study period. 
150

151

152

153

154

155

156

157

158

159

160

161

162

Patients $>16$ years admitted to Antrim hospital over the period Jan 2012-Dec 2013 and was specified as one of the following:

- Positive-MRGN patient

- Matched control patient

- Randomly selected control patient

\section{Study exclusion criteria}

The following patients were excluded:

- paediatric patients (i.e. patients under the age of 16 years)

- patients with scheduled admissions

\section{Data linkage}

Data for the case participants and the two sets of control patients were linked to the Health and Social Care Business Services Organisation (BSO; Northern Ireland) primary care prescription records of antibiotic use within primary care over the previous 12 months.

\section{Microbiology data}

Details on MRGN isolates were obtained from the Northern Health Trust clinical microbiology computerized record systems over the two year study period. Hospital detected MRGN throughout this paper refer to isolates that were recovered during the patient's hospital stay (hospital-onset and community-onset). Only the first unique positive MRGN isolates for individual patients, throughout the study period, were recorded (i.e. duplicated positive results were excluded). For the detection of MRGN, the methodology of the European Committee on Antimicrobial Susceptibility Testing (EUCAST) was routinely employed within the hospital $[4,18,23]$. Each patient was labelled as having community-onset MRGN when he/she had the organism(s) detected within the first 48 hours after hospital admission or with hospital-onset MRGN when this detection occurred 48 hours or more after hospital admission. 
175 The patients chosen for this study consisted of a convenience sample and included all cases over a two-

176 year study period. The following statistical procedures were performed in phase 1: Data relating to

177 previous antibiotic exposure and other risk factors were summarised using descriptive statistics.

178 Previous antibiotic prescribing in the primary care setting was measured (i.e. presented as cumulative

179 count of treatment courses) during the periods: 0-3 months, 0-6 months and 0-12 months prior to

180 admission. For the purposes of statistical analyses, in line with agents that have been found to be

181 associated with identification of MRGN in previous international research, antibiotics were categorised

182 into penicillin combinations, fluoroquinolones, second and third generation cephalosporins and

183 macrolides. To identify any association between previous antibiotic exposure and hospital detected

184 MRGN incidence rates in the hospitalised patients, univariate analyses were conducted as follows: (i)

185 to evaluate associations between the continuous variables, either the Student paired t-test or the

186 Wilcoxon test was carried out, based on the normality of data distribution; and (ii) the McNemar's test

187 was used with categorical variables. Following this, a backward multivariate logistic regression was

188 carried out [with the outcome: MRGN (yes/no)] using the following models, to identify significant

189 variables: Model (1a) included the antibiotic groups of interest prescribed in primary care over the 3

190 months prior to admission together with all non-antibiotic risk factors which exhibited a $\mathrm{P}$ value of

1910.25 or lower on univariate analyses; $\underline{\operatorname{Model}(1 \mathrm{~b})}$ covered the same ground for antibiotics prescribed in

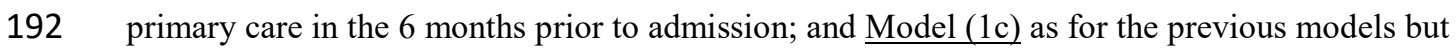

193 covering the period of the 12 months prior to admission. To measure the influence of each explanatory

194 variable (e.g. previous antibiotic use or other risk factors) on the dependent variable (hospital detected

195 MRGN), odds ratios were utilised. All variables which resulted in a significance level of $\mathrm{P} \leq 0.05$ in the

196 multivariate models were deemed statistically significant. In phase 2, a similar statistical approach to

197 that outlined above was repeated using the second control group, the only difference being that for

198 univariate analysis, to evaluate associations between the continuous variables, either the Student t-test

199 or the Mann-Whitney U-test was carried out, based on the normality of data distribution while the

200 Pearson Chi Square was used with categorical variables. Similar statistical approaches to that

201 mentioned above (in phase 1 and phase 2) were repeated to examine the impact of antibiotic

202 prescribing in primary care on isolation of hospital-onset MRGN and community-onset MRGN within 


\section{Results}

\section{Study population}

207

In total, 183 MRGN isolates were recovered from hospitalised patients within the AAH, between January 2012 and December 2013. The overall prevalence rate of MRGN was 0.088 cases/100 bed-days ( $0.74 \%)$. After applying the study inclusion criteria, 98 unique patients harbouring MRGN were eligible, and comprised the study cases group (Table 1). Of these 98 patients, 54 (55.1\%) were identified as having a community-onset detection; while $44(44.9 \%)$ were defined as having a hospital-onset detection. Of interest, the mean time from admission to detection of MRGN bacteria was 6 days (Table 1).

\section{Microbiological characteristics of MRGN strains}

E. coli was found to be the most frequently (75.3\%) detected pathogen among the MRGN organisms, followed by, in descending order, Klebsiella pneumoniae (8.2\%), Coliforms (8.2\%), Proteus mirabilis (3.1\%), Morganella morganii (2.1\%), Klebsiella oxytoca (1.0\%), Enterobacter aerogens (1.0\%) and Enterobacter cloacae (1.0\%; Table1).

\section{Antibiotic prescribing in primary care}

The most commonly prescribed antibiotics, i.e. average number of treatment courses (the count of antibiotic items prescribed to a given patient) in primary care for the case and matched control patients (Phase 1; Figure 1) during the 0-12 month period was found to be cephalosporin antibiotics (cases: 1.82; matched controls: 0.45). Data for Phase 2 (Figure 1) shows that cephalosporin antibiotics were again the most frequently prescribed antibiotics, during the $0-12$ month period in primary care. The case patients received a mean of 1.82 treatment courses, while a mean of 0.46 treatment courses was dispensed to the randomly selected control patients. 
227 Fig. 1 Average number of antibiotic treatment courses (of second and third generation cephalosporins,

228 fluoroquinolones, penicillin combinations and macrolides), which were prescribed for the cases, matched

229 (phase 1) and randomly selected control patients (phase 2) in primary care, during the previous 3 month,

2306 month and 12 month periods.

231 Clinical and general characteristics of study population

\section{Phase 1 cohort}

233

234

In phase 1, 196 patients without an MRGN bacterial isolation were matched and compared with the 98

MRGN cases. The data in Table 2 shows that the matching of the selected parameters age, gender, admission ward and age-adjusted Charlson co-morbidity index was carried out effectively. Further details on the demographics and baseline characteristics of the cases and control groups in phase 1 are also presented in Table 2 .

\section{Phase 2 cohort}

In phases 2, a total of 200 patients (with no MRGN) were selected randomly, to comprise the second control group. Out of the 98 case patients and 200 control patients, $64.3 \%$ and $53.0 \%$ were female, respectively. The mean age was found to be higher ( 73.3 years) in case patients compared to control patients (61.1 years). The mean age-adjusted Charlson co-morbidity index score was higher (3.8), in case patients compared to control patients (2.9). When mean hospitalisation period of case patients was compared with that in control patients, the difference was large (cases: 13.6 days; control: 5.0 days). Further demographic and baseline characteristics of the control groups in phase 2, are also presented in Table 2.

\section{Univariate analysis of variables associated with MRGN bacteria}

In phase 1 and 2, individual relationships were identified between MRGN detected in hospital and variables with $\mathrm{P}$ values $\leq 0.25$, as displayed in Table 2 . 
Phase 1 (matched controls)-3 month model (model 1a)

254

The multivariate analysis model for this category, identified that a prolonged hospitalisation period and having a primary diagnosis of a genitourinary system disease(s) were independent predictors for hospital detected MRGN. The presence of genitourinary disease (genitourinary infectious diseases were excluded) in hospitalised patients was found to be associated with a $443.0 \%$ increase in the likelihood of identification of a hospital detected MRGN bacteria (coefficient 1.489; CI 95\% 1.5113.00; $\mathrm{P}=0.007$; Table 3). Additionally, for every one day increase in length of hospital stay, there was a 4.0\% higher risk of isolation of MRGN while hospitalised (coefficient 0.040; CI 95\% 1.02-1.06; $\mathrm{P}<0.001)$.

\section{Phase 1 (matched controls)-6 month model (model 1b)}

The multivariate analysis of variables (included this model) determined that per each one day increase in period of stay in hospital, the odds of hospital MRGN detection was greater by $4.0 \%$ (coefficient 0.041, CI 95\% 1.02-1.07, P < 0.001; Table 3).

\section{Phase 1 (matched controls)-12 month model (model 1c)}

Multivariate analysis for model $1 \mathrm{c}$, revealed that previous prescription of a fluoroquinolone or a cephalosporin (second and third generation) in primary care during the prior 12 month period was significantly and independently associated with the isolation of MRGN while hospitalised. For each prescribed treatment course of a fluoroquinolone, the risk of identification of MRGN in hospital was found to be higher by $55.0 \%$ (coefficient 0.438 ; CI 95\% 1.06-2.26; $\mathrm{P}=0.023$ ). In relation to previous exposure to second and third generation cephalosporins, per each increase in the number of courses prescribed, the likelihood of isolation of hospital MRGN increased by $19.0 \%$ (coefficient 0.177 ; CI 95\% 1.06-1.35; $\mathrm{P}=0.004$; Table 3). 
This cohort resulted in the identification of additional variables (i.e. 'non-antibiotic' host-related factors) which could not be identified in phase 1 of the study due to the variables being used as matching criteria. The results of multivariate analysis, using models $2 \mathrm{a}, 2 \mathrm{~b}$ and $2 \mathrm{c}$, were found to be exactly the same. The following variables were indicated as potential independent predictors for hospital detected MRGN: having a higher age, longer hospitalisation period, being diagnosed primarily with genitourinary disease(s) and being female (226.0\% greater in hospitalised female patients, compared with hospitalised male patients; coefficient 0.813; CI 95\% 1.25-4.06; P = 0.007). Genitourinary underlying disease(s) as a primary diagnosis resulted in a $756.0 \%$ higher likelihood of producing MRGN isolates during the hospital stay (coefficient 2.022; CI 95\% 2.54-22.45; $\mathrm{P}<0.001$ ). An increase in age (by one year over the age 16 years old) led to a $4.0 \%$ increase in risk of detection of MRGN bacteria in hospital (coefficient 0.037; CI 95\% 1.02-1.06; $\mathrm{P}<0.001$ ). For each one day rise in length of hospital stay, the odds of recovery of hospital MRGN rose by $6.0 \%$ (coefficient 0.053 ; CI 95\%; 1.03-1.09; P < 0.001; Table 3).

\section{Discussion}

In the United States in studies published in 2013 and 2014, approximately 3.9\% of community-onset

293 Escherichia coli infection strains have been determined to be producers of ESBLs [4, 24]. In the

294 United Kingdom, the proportion of MRGN Escherichia coli strains increased from $0.8 \%$ in 2002 to

$29511.2 \%$ in 2006; there was also an increase in prevalence rate of MRGN Klebsiella pneumoniae isolates 296 in the UK over the same period (from $0.4 \%$ to $10.1 \%$ ) [25]. A systematic review and meta analysis 297 conducted in July 2015 showed that the prevalence of MRGN (pooled) was higher in Africa and Asia 298 (ranging from 15\% to 46\%,) and lower in the Americas (2\%) northern (4\%), and southern (6\%), and 299 central (3\%) Europe [26]. conditions, such as pharyngitis, sinus infections, middle ear infections, viral upper respiratory infections (i.e., the "common cold"), bronchitis, bronchiolitis, asthma, allergies, influenza, and pneumonia. Beyond respiratory conditions, a number of other conditions are commonly treated with 
antibiotics in outpatient settings, including urinary tract infections (UTIs), skin infections, and acne

In the present study, the majority of MRGN isolates were documented to be Escherichia coli bacteria and the most frequent specimen was urine. It is well documented that there are reservoirs of resistant Escherichia coli isolates within community settings and that organisms can be 'imported' into hospitals when patients are admitted [26, 28].

The majority of previous studies that assessed the determinants of MRGN bacteria have neglected vital issues that need to be addressed, including 'dose-accumulation', i.e. the time-dependent impact of prior treatment with antibiotics on the emergence of MRGN isolates in the primary and secondary care settings. In most prior studies antibiotic use has been included as a qualitative (dichotomous) variable, and data on prior antibiotic use in primary care have been collected over relatively short inpatient stay periods or within a short time frame of between 1 and 6 months, prior to the MRGN detection in hospital $[8,29]$. cephalosporin antibiotic group (second and third generation) and the fluoroquinolone antibiotic group (during the previous 12 month period as outpatients) were independent predictors for the detection of MRGN bacteria in hospital. In 2011, a population based study (i.e. ecological in design) was conducted to assess the relationship between antibiotic prescribing in the community and the incidence of hospital detected MRGN in the present study site (AAH). The analysis of data in the latter ecologic-level research demonstrated a significant positive association (with a lag of 4 months) between the prescribing of amoxicillin-clavulanic acid, in primary care, and the incidence of hospital detected MRGN [18]. In a study performed in Switzerland (published in 2011), which investigated the influence of fluoroquinolone prescribing on antibiotic-resistant Escherichia coli strains, a temporal association between the incidence of community fluoroquinolone-resistant Escherichia coli isolates and community ciprofloxacin consumption was documented. In addition, variations in the use of certain antibiotic agents were followed by subsequent variations in cefepime resistance rates in Escherichia coli strains. The antibiotics implicated included outpatient ciprofloxacin use (with a lag of 4 months) [30, 31]. These latter studies were ecological in design and therefore were subject to ecological bias. In the ecological 
level study. These confounding effects may have weakened the results of the latter population based

333 study, i.e. findings of ecological studies are deemed less valid and less generalizable. In contrast, patient-

334 level studies yield more biologically plausible outcomes [8, 29-32].

335 The following non-antibiotic host-related risk factors were determined as independent predictors of

336 MRGN detection in hospital: the presence of genitourinary underlying disease (as a primary diagnosis),

337 being female, being elderly and having an extended in-hospital stay. When a host's immune system is

338 suppressed, accompanied by the occurrence of neutropenia due, for example, to the administration of

339 chemotherapy, being elderly, being a neonate or having immune deficiency syndrome, the vulnerability

340 of the host to acquire resistant bacterial strains is enhanced [10,33-35]. In the present study, female

341 patients were shown to be significantly more likely to be in the case group than in the randomly

342 selected control group. The pathophysiology of urinary tract infections within female patients may

343 potentially explain this finding [35-37]. Nonetheless, in the present study being female was significant

344 in itself, independent of having a urinary tract disorder as the primary diagnosis. In the present study,

345 there was a firm linkage between having an extended hospitalisation period and the recovery rate of

346 MRGN in hospital. Several previous studies have also reported this latter relationship $[8,10]$. The

347 methodology used was unable to differentiate whether the longer stay was due to the MRGN isolation

348 or whether the MRGN detection was directly linked to length of stay.

\section{Strengths and limitations of study}

350 This study has several strengths. Firstly, a large overall sample size of patients was examined. Most

351 previously published studies have been more limited in scope. Secondly, the data used were primarily

352 recorded for another purpose, i.e. data were recorded as part of routine practice, which, in turn,

353 minimised information bias. Thirdly, this study was performed in two stages. This latter technique

354 allowed the identification of further patient-related predictors for the isolation of MRGN organisms.

355 Fourthly, the data utilised in the present investigation was gathered at the individual patient level. The

356 majority of previous studies had ecologic designs. Notably, this study is unique in this area of research

357 due to following: (i) this was the first patient-level study in the United Kingdom that connected

358 previous antibiotic prescribing in outpatients with MRGN identification in hospital and (ii) the data 

Services databases and surveillance systems. variation of infection control practices that were in the place in the study site hospital during the study period. The performance indicator reports generated by the infection control team within AAH, however, showed that the monthly compliance rate to hand hygiene and environmental decontamination among the hospital staff was approximately $99.0 \%$ and $93 \%$ respectively across the study period. These data present confidence that cross-contamination rates were likely to be low in the study site hospital over the study period, i.e. the rate of MRGN transmission (from patient to patient) was low. It was not possible to control for exposure to antibiotics during the hospital stay. Accounting for travel or overseas infection acquisition was also not possible. There was no possibility to report the patients who were identified as carriers of an MRGN during a previous hospital stay. It was not possible to count and compare the number of clinical samples taken from control groups against case patient group (i.e., as there was no MRGN screening policy in NHSCT), some controls might be false negative. These latter factors may partially explain the percentage of variance that was unaccounted for in the logistic regression modelling. Furthermore, in the present study, the antibiotic dispensing in primary care was used as a surrogate of antibiotic exposure in individual patients. This may have resulted in an overestimation of antibiotic use as non-adherence to full courses of antibiotics is well documented.

\section{Conclusion}

379 The study identified the independent association between previous exposure (in primary care) to certain antibiotic groups (second and third generation cephalosporins and fluoroquinolones) and the prevalence rate of MRGN bacteria detected in secondary care. The results of this study also demonstrated that the following 'non-antibiotic' factors are independently associated with the detection of MRGN bacteria in hospital: prolonged hospitalisation, being female, presence of genitourinary disease (as a primary diagnosis) and older age. The study also benchmarked the prevalence rate of MRGN pathogens in a 

selection of MRGNs, adherence to "antibiotic stewardship" and/or antibiotic guidelines is essential.

\section{Acknowledgments}

389 The authors would like to acknowledge the help provided by the staff of the Honest Broker Service 390 (HBS) within the Business Services Organisation Northern Ireland (BSO). The HBS is funded by the 391 BSO and the Department of Health, Social Services and Public Safety for Northern Ireland 392 (DHSSPSNI). The authors alone are responsible for the interpretation of the data and any views or 393 opinions presented are solely those of the authors and do not necessarily represent those of the BSO.

$394 \quad$ Funding

395 This research received no specific grant from any funding agency, commercial or not-for-profit sectors.

\section{Conflict of interest}

397 The authors declare no conflicts of interest with respect to authorship and/or publication of this article.

\section{Ethical approval}

399 All procedures performed in this study involving human participants were in accordance with the 400 ethical standards of the institutional and/or national research committees and with the 1964 Helsinki declaration and its later amendments or comparable ethical standards. For the purposes of conducting this study, governance approvals were obtained from: the Office for Research Ethics Committees Northern Ireland [ORECNI; reference: 14/NI/0065], the Governance Research Office in the Northern

404 Health and Social Care Trust [reference: NRP14-0417-04] and the Honest Broker Governance Board [reference: 002/14]. For this type of study (retrospective in design), formal individual patient consent was not required. 
1. Bush K. Past and Present Perspectives on $\beta$-Lactamases. Antimicrobial Agents and Chemotherapy. 2018 Sep 24;62(10); https://doi: 10.1128/AAC.01076-18. Print 2018 Oct.

2. Russell-Goldman E, Burke L, Humphreys H, Gilleece A, Fitzgerald-Hughes D, O' Neill E. Clinical features and molecular epidemiology of extended-spectrum B-lactamases-producing Enterobacteriaceae: the hidden messages. Journal of Medical Microbiology. 2013; 62: 1768-4.

3. Siedelman L, Kline L. Duval S. Risk factors for community- and health facility-acquired extended-spectrum $\beta$-lactamase-producing bacterial infections in patients at the University of Minnesota Medical Center, Fairview. American Journal of Infection Control. 2013; 40: 849-4.

4. Rogers BA. (on behalf of the Australasian Society for Infectious Diseases Clinical Research Network) Community-onset Escherichia coli infection resistant to expanded-spectrum cephalosporins in low-prevalence countries. Antimicrobial Agents and Chemotherapy. 2014; 58: 2126-10.

5. Rodríguez-Baño J. Risk-factors for emerging bloodstream infections caused by extendedspectrum beta-lactamase-producing Escherichia coli. Clinical Microbiology and Infection. 2008; $14: 180-4$.

6. Branger C, Ledda A, Billard-Pomares T, Doublet B, Fouteau S, Barbe V, Roche D, et al. Extended-spectrum $\beta$-lactamase-encoding genes are spreading on a wide range of Escherichia coli plasmids existing prior to the use of third-generation cephalosporins. Microbial Genomics. 2018 Sep;4(9); https:// doi: 10.1099/mgen.0.000203. Epub 2018 Aug.

7. R odriguez-Bano J, Picon E, Gijon P, Hernandez JR, Ruiz M, Pena G, et al. Community-onset bacteraemia due to extended spectrum B-lactamase-producing E. coli: Risk factors and prognosis. Clinical infectious diseases. 2010; 50: 40-8.

8. Kritsotakis EI, Tsioutis C, Roumbelaki M, Christidou A, Gikas A. Antibiotic use and the risk of carbapenem-resistant extended-spectrum- lactamase-producing Klebsiella pneumoniae infection in hospitalized patients: results of a double case-control study. Journal of Antimicrobial Chemotherapy. 2011; 66: 1383-8.

9. Oli AN, Eze DE, Gugu TH, Ezeobi I, Maduagwu UN, Ihekwereme CP. Multi-antibiotic resistant extended-spectrum beta-lactamase producing bacteria pose a challenge to the effective treatment of wound and skin infections. Pan African Medical Journal. 2017; 27: 66.

10. Artero A, Esparcia A, Alberola J, Madrazo M, Nogueira JM, Eiros JM. Prospective cohort study of risk factors for extended-spectrum B-lactamase-producing Escherichia coli urinary tract infections in elderly patients admitted to hospital. International Journal of Clinical Practice. 2017 Sep; 71(9). Epub 2017 Sep 5

11. Steiger SN, Comito RR, Nicolau DP. Clinical and economic implications of urinary tract infections. Expert Review of Pharmacoeconomics \& Outcomes Research. 2017 Aug; 17(4): 377-6.

12. Pitout JDD, Laupland KB. Extended-spectrum beta-lactamase-producing Enterobacteriaceae: an emerging public-health concern. Lancet Infectious Diseases. 2008; 8: 159-7.

13. Kang C, Wi YM, Ko KS, Chung DR, Peck KR, Lee NY, Song J. Outcomes and risk factors for mortality in community-onset bacteraemia caused by extended-spectrum beta-lactamaseproducing Escherichia coli, with a special emphasis on antimicrobial therapy. Scandinavian Journal of Infectious Diseases. 2013; 45: 519-7.

14. Castillo-Tokumori F, Irey-Salgado C, Málaga G. Worrisome high frequency of extendedspectrum beta-lactamase-producing Escherichia coli in community-acquired urinary tract infections: a case-control study. International Journal of Infectious Diseases. 2017 Feb; 55:164.

15. Cooper BS, Medley GF, Stone SP. Methicillin-resistant Staphylococcus aureus in hospitals and the community: Stealth dynamics and control catastrophes. Proceedings of the National Academy of Sciences. 2004; 101: 10223-8. 
16. Gallini A, Degris A, Desplas M, Bourrel R, Archambaud M, Montastruc JL, et al. Inlfluence of fluoroquinolone consumption in inpatients and outpatients on ciprofloxacin-resistant Escherichia coli in a university hospital. Journal of Antimicrobial Chemotherapy. 2010; 65: 2650-8.

17. Lopez-Lozano JM, Monnet DL, Yague A, Burgos A, Gonzalo N, Campillos P. et al. Modelling and forecasting antimicrobial resistance and its dynamic relationship to antimicrobial use a time-series analysis. International Journal of Antimicrobial Agents. 2000; 14: 21-10.

18. Aldeyab MA, Harbarth S, Vernaz N, Kearney MP, Scott MG, Darwish FW, et al. The impact of antibiotic use on the incidence and resistance pattern of extended-spectrum beta-lactamaseproducing bacteria in primary and secondary healthcare settings. British Journal of Clinical Pharmacology. 2012; 74: 171-9.

19. Exner M, Bhattacharya S, Christiansen B, Gebel J, Goroncy-Bermes P, Hartemann P, Heeg P, et al. Antibiotic resistance: What is so special about multidrug-resistant Gram-negative bacteria. GMS Hygiene and Infection Control. 2017; 12: 1-24.

20. Ramiarina RA, Ramiarina BL, Almeida RM, Pereira WCD Comorbidity adjustment index for the international classification of diseases, 10th revision. Revista de Saúde Pública. 2008; 42: 590-7.

21. Charlson ME, Pompei P, Ales KL, MacKenzie CR. A new method of classifying prognostic co-morbidity in longitudinal studies: development and validation. Journal of Chronic Diseases. 1987; 40: 373-82.

22. Random Integer Generator. https:// www.random.org/integers. Accessed October 2014.

23. European Committee on Antimicrobial Susceptibility Testing (EUCAST). Clinical breakpointsbacteria. 2011. http://www.eucast.org. Accessed October 2014.

24. Doi Y, Park YS, Rivera JI, Adams-Haduch JM, Hingwe J, Sordillo E.M, et al. Communityassociated extended-spectrum beta-lactamase-producing E. coli infection in the United State. Clinical Infectious Diseases. 2013; 56: 641-9.

25. Livermore DM. Declining cephalosporin and fluoroquinolone non-susceptibility among bloodstream Enterobacteriaceae from the UK: links to prescribing change? Journal of Antimicrobial Chemotherapy. 2013; 68: 2667-8.

26. Karanika S, Karantanos T, Arvanitis M, Grigoras C, Mylonakis E. Fecal Colonization with Extended-spectrum Beta-Lactamase-Producing Enterobacteriaceae and Risk Factors Among Healthy Individuals: A Systematic Review and Metaanalysis. Clinical Infectious Diseases. 2016 Aug 1; 63(3):310-8.

27. A report from the PEW charitable trusts. Antibiotic use in outpatient settings. Health experts create national targets to reduce unnecessary antibiotic prescriptions. May 2016. Accessed January 2019 https://www.pewtrusts.org//media/assets/2016/05/antibioticuseinoutpatientsettings.pdf

28. Birgy A, Levy C, Bidet P, Thollot F, Derkx V, Béchet S, et al. ESBL-producing Escherichia coli ST131 versus non-ST131: evolution and risk factors of carriage among French children in the community between 2010 and 2015. Journal of Antimicrobial Chemotherapy. 2016 Oct; 71(10): 2949-7.

29. D'Agata EM. (2005) Methodological issues of case-control studies: a review of established and newly recognised limitations. Infection Control and Hospital Epidemiology. 26: 388-41.

30. MacDougall C, Powell, J, Johnson C, Edmond M Polk R. Hospital and community fluoroquinolone use and resistance in Staphylococcus aureus and Escherichia coli in 17 US hospitals. Clinical Infectious Diseases. 2005; 41: 435-6.

31. Vernaz N, Huttner B, Muscionico D, Salomon JL, Bonnabry P, Lopez-Lozano JM, et al. Modelling the impact of antibiotic use on antibiotic-resistant Escherichia coli using populationbases data from a large hospital and its surrounding community. Journal of Antimicrobial Chemotherapy. 2011; 66: 928-7. 
32. Augustine MR, Testerman TL, Justo JA, Bookstaver PB, Kohn J, Albrecht H, et al. Clinical Risk Score for Prediction of Extended-Spectrum $\beta$-Lactamase-Producing Enterobacteriaceae in Bloodstream Isolates. Infection Control \& Hospital Epidemiology. 2017 Mar; 38(3): 266-7.

33. Crogan N, Evans BC. Clostridium difficile: An emerging epidemic in nursing homes. Geriatric Nursing. 2007; 28: 161-5.

34. Carroll KC, Bartlett JG. Biology of Clostridium difficile: Implications for epidemiology and diagnosis. Annual Review of Microbiology. 2011; 65: 501-20.

35. Ishida $\mathrm{T}$, Ito A, Washio $\mathrm{Y}$, Yamazaki A, Noyama M, Tokioka F, et al. Risk factors for drugresistant pathogens in immunocompetent patients with pneumonia: Evaluation of PES pathogens. Journal of Infection and Chemotherapy. 2017 Jan; 23(1): 23-6.

36. Wells BG, DiPiro JT, Schwinghammer TL, DiPiro CV. Pharmacotherapy Handbook, Seventh Edition. McGraw-Hill Medical; 2008. pp. 544-555.

37. Pérez Heras I, Sanchez-Gomez JC, Beneyto-Martin P, Ruano-de-Pablo L, Losada-Pinedo B. Community-onset extended-spectrum $\beta$-lactamase producing Escherichia coli in urinary tract infections in children from 2015 to 2016: Prevalence, risk factors, and resistances. Medicine (Baltimore). 2017 Dec; 96(50): e8571. 
Table 1 Microbiological characteristics of the MRGN isolates recovered from the case patients in Antrim Area Hospital (January 2012 to December 2013).

\begin{tabular}{|c|c|}
\hline Characteristics & Number $(\%)$ \\
\hline \multicolumn{2}{|l|}{ Isolate type $(n=98)$} \\
\hline - E. coli & $73(75.3)$ \\
\hline - K. pneumoniae & $8(8.2)$ \\
\hline - $\quad$ K. oxytoca & $1(1.0)$ \\
\hline - Coliforms ${ }^{a}$ & $8(8.2)$ \\
\hline - $\quad$ P. mirabilis & $3(3.1)$ \\
\hline - M. morganii & $2(2.1)$ \\
\hline - E. aerogenes & $1(1.0)$ \\
\hline - E. cloacae & $1(1.0)$ \\
\hline - Unknown/undetermined & $1(1.0)$ \\
\hline \multicolumn{2}{|l|}{ Isolate culture site $(n=98)$} \\
\hline - Urine & $65(66.3)$ \\
\hline - Blood & $9(9.2)$ \\
\hline - Wound & $7(7.1)$ \\
\hline - $\quad$ Sputum & $4(4.1)$ \\
\hline - Other & $13(13.3)$ \\
\hline \multicolumn{2}{|l|}{ Isolate origin/source $(n=98)$} \\
\hline - Hospital-onset $^{\mathbf{b}}$ & $44(44.9)$ \\
\hline - Community-onset $^{\mathbf{c}}$ & $54(55.1)$ \\
\hline $\begin{array}{l}\text { Time to MRGN detection } \\
\text { Mean, days (CI 95\%) }\end{array}$ & $6.0(4.2-7.8)$ \\
\hline
\end{tabular}

${ }^{\mathrm{a}}$ Refers to unidentified gram-negative rod bacterial isolates, i.e. these isolates were tested for ESBL production

${ }^{\mathbf{b}}$ Classified when MRGN stain recovered 48 hours or more after hospital admission

${ }^{\mathbf{c}}$ Classified when MRGN isolate recovered $<48$ hours after hospital admission

d Time from hospital admission to MRGN isolation. 


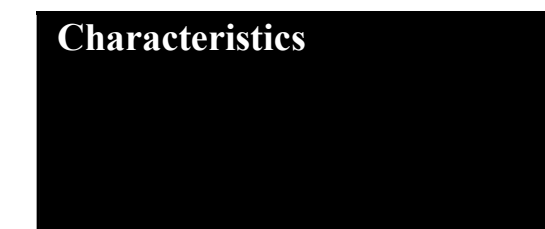

\begin{tabular}{|cccccc|}
\hline Age, mean (SD), years & $73.3(15.4)$ & $72.2(16.7)$ & $<\mathbf{0 . 1 5 5}$ & $61.1(20.9)$ & $<\mathbf{0 . 0 0 1}$ \\
\hline Age category, n (\%) & & & $<0.309$ & & $<\mathbf{0 . 0 0 1}$ \\
\hline$\bullet \quad 16-65$ & $23(23.5)$ & $49(25.0)$ & & $96(48.0)$ & \\
\hline$\bullet \quad>65$ & $75(76.5)$ & $147(75.0)$ & & $104(52.0)$ & \\
\hline $\begin{array}{l}\text { Age-adjusted Charlson } \\
\text { co-morbidity index score, } \\
\text { mean }(\mathbf{S D})\end{array}$ & $3.8(1.9)$ & $3.7(1.5)$ & $<0.712$ & $2.9(2.0)$ & $<\mathbf{0 . 0 0 1}$ \\
\end{tabular}

$\begin{array}{ccc}\text { Case } & \text { Matched } & \text { P } \\ \text { patients } & \text { control } & \text { value } \\ (\mathrm{n}=98) & \text { patients } \\ & (\mathrm{n}=196) & \end{array}$

Randomly P value selected control patients $(n=200)$ 1.000

0.065

\begin{tabular}{llll}
\hline Gender, n (\%) & 1.000 & $\mathbf{0 . 0 6 5}$ \\
\hline
\end{tabular}

\begin{tabular}{|c|c|c|c|c|c|}
\hline - Male & $35(35.7)$ & $70(35.7)$ & \multicolumn{3}{|c|}{$94(47.0)$} \\
\hline - $\quad$ Female & $63(64.3)$ & $126(64.3)$ & \multicolumn{3}{|c|}{$106(53.0)$} \\
\hline $\begin{array}{l}\text { Length of in-hospital stay, } \\
\text { mean (SD), days }\end{array}$ & $13.6(16.3)$ & $7.6(9.1)$ & $<0.001$ & $5.0(11.1)$ & $<0.001$ \\
\hline Admission ward, n (\%) & & & 1.000 & & 0.001 \\
\hline - $\quad \mathrm{A} \& \mathrm{E}$ & $19(19.4)$ & $38(19.4)$ & \multicolumn{3}{|c|}{$52(26.0)$} \\
\hline - $\quad \mathrm{B} 1$ & $31(31.6)$ & $62(31.6)$ & \multicolumn{3}{|c|}{$27(13.5)$} \\
\hline - $\mathrm{B} 2$ & $16(16.3)$ & $32(16.3)$ & \multicolumn{3}{|c|}{$26(13.0)$} \\
\hline - $\mathrm{C} 5$ & $5(5.1)$ & $10(5.1)$ & \multicolumn{3}{|c|}{$17(8.5)$} \\
\hline - $\mathrm{C6}$ & $10(10.2)$ & $20(10.2)$ & \multicolumn{3}{|c|}{$12(6.0)$} \\
\hline - Other & $17(17.3)$ & $34(17.3)$ & \multicolumn{3}{|c|}{$66(33.0)$} \\
\hline Medical specialty, n (\%) & & & $<0.001$ & & $<0.001$ \\
\hline $\begin{array}{ll} & \text { Medicine } \\
& \text { assessment unit }\end{array}$ & $12(12.2)$ & $24(12.2)$ & \multicolumn{3}{|c|}{$19(9.5)$} \\
\hline $\begin{array}{l}\text { - Care of older } \\
\text { people }\end{array}$ & $4(4.1)$ & $12(6.1)$ & \multicolumn{3}{|c|}{$10(5.0)$} \\
\hline - General medicine & $41(41.8)$ & $80(40.8)$ & \multicolumn{3}{|c|}{$53(26.5)$} \\
\hline - General surgery & $15(15.3)$ & $33(16.8)$ & \multicolumn{3}{|c|}{$30(15.0)$} \\
\hline - $\quad$ Thoracic medicine & $6(6.1)$ & $7(3.6)$ & \multicolumn{3}{|c|}{$7(3.5)$} \\
\hline - $\quad \mathrm{A} \& \mathrm{E}$ & $1(1.0)$ & $4(2.0)$ & \multicolumn{3}{|c|}{$31(15.5)$} \\
\hline - $\quad$ Cardiology & $3(3.1)$ & $3(1.5)$ & \multicolumn{3}{|c|}{$23(11.5)$} \\
\hline - Other & $16(16.3)$ & $33(16.8)$ & \multicolumn{3}{|c|}{$27(13.5)$} \\
\hline
\end{tabular}




\begin{tabular}{|c|c|c|c|c|c|}
\hline Characteristics & $\begin{array}{c}\text { Case } \\
\text { patients } \\
(\mathrm{n}=98)\end{array}$ & $\begin{array}{l}\text { Matched } \\
\text { control } \\
\text { patients } \\
(\mathrm{n}=196)\end{array}$ & $\begin{array}{c}\mathbf{P} \\
\text { value }\end{array}$ & $\begin{array}{l}\text { Randomly } \\
\text { selected } \\
\text { control } \\
\text { patients } \\
(\mathrm{n}=\mathbf{2 0 0})\end{array}$ & $P$ value \\
\hline $\begin{array}{l}\text { Primary underlying } \\
\text { disease }^{\mathrm{a}}, \mathrm{n}(\%)\end{array}$ & & & $<0.001$ & & 0.001 \\
\hline - $\quad$ Circulatory system & $9(9.2)$ & $22(11.2)$ & & $31(15.5)$ & \\
\hline - $\quad$ Respiratory system & $22(22.4)$ & $48(24.5)$ & & $25(12.5)$ & \\
\hline - Digestive system & $12(12.2)$ & $35(17.9)$ & & $25(12.5)$ & \\
\hline - Genitourinary system & $22(22.4)$ & $12(6.1)$ & & $16(8.0)$ & \\
\hline - Injury, poisoning & $7(7.1)$ & $19(9.7)$ & & $25(12.5)$ & \\
\hline - Other & $26(26.5)$ & $60(30.6)$ & & $78(39.0)$ & \\
\hline $\begin{array}{l}\text { Secondary underlying } \\
\text { disease }^{\text {a }} \text {, n (\%) }\end{array}$ & & & $<0.001$ & & 0.007 \\
\hline - $\quad$ Circulatory system & $12(12.2)$ & $31(15.8)$ & & $36(18.0)$ & \\
\hline - $\quad$ Respiratory system & $6(6.1)$ & $20(10.2)$ & & $12(6.0)$ & \\
\hline - $\quad$ Digestive system & $5(5.1)$ & $20(10.2)$ & & $6(3.0)$ & \\
\hline - Genitourinary system & $16(16.3)$ & $13(6.6)$ & & $8(4.0)$ & \\
\hline $\begin{array}{ll}\text { - } & \begin{array}{l}\text { External causes of } \\
\text { morbidity/mortality }\end{array} \\
\end{array}$ & $9(9.2)$ & $22(11.2)$ & & $29(14.5)$ & \\
\hline $\begin{array}{l}\text { Endocrine, } \\
\text { nutritional disorders }\end{array}$ & $7(7.1)$ & $9(4.6)$ & & $10(5.0)$ & \\
\hline - Other & $43(43.8)$ & $81(41.3)$ & & $99(49.5)$ & \\
\hline \multicolumn{6}{|l|}{$\begin{array}{l}\text { Cephalosporin courses }{ }^{b} \text {, } \\
\text { mean (SD); total number }\end{array}$} \\
\hline $\begin{array}{ll}\text { - Preceding } 3 \text { month } \\
\text { period }\end{array}$ & $\begin{array}{c}0.02 \\
(0.20) ; 2.0 \\
\end{array}$ & $\begin{array}{c}0.00(0.00) \\
0.0\end{array}$ & $<0.001$ & $\begin{array}{c}0.00(0.00) \\
0.0\end{array}$ & 0.154 \\
\hline $\begin{array}{ll}\text { - } & \text { Preceding } 6 \text { month } \\
\text { period }\end{array}$ & $\begin{array}{c}0.04 \\
(0.28) ; 4.0 \\
\end{array}$ & $\begin{array}{c}0.01(0.14) ; \\
2.0\end{array}$ & $<0.001$ & $\begin{array}{c}0.00(0.00) ; \\
0.0\end{array}$ & 0.044 \\
\hline $\begin{array}{l}\text { Preceding } 12 \text { month } \\
\text { period }\end{array}$ & $\begin{array}{c}1.82 \\
(4.28) ; \\
178.0\end{array}$ & $\begin{array}{l}0.45(1.81) \\
88.0\end{array}$ & 0.039 & $\begin{array}{l}0.46(2.14) \\
92.0\end{array}$ & $<0.001$ \\
\hline
\end{tabular}




\begin{tabular}{|c|c|c|c|c|c|}
\hline Characteristics & $\begin{array}{c}\text { Case } \\
\text { patients } \\
(n=98)\end{array}$ & $\begin{array}{l}\text { Control } \\
\text { patients } \\
(n=196)\end{array}$ & $P$ value & $\begin{array}{l}\text { Randomly } \\
\text { selected } \\
\text { control } \\
\text { patients } \\
(\mathrm{n}=\mathbf{2 0 0})\end{array}$ & $\begin{array}{c}p \\
\text { value }\end{array}$ \\
\hline \multicolumn{6}{|l|}{$\begin{array}{l}\text { Penicillin combination } \\
\text { courses, }{ }^{b} \text { mean (SD); } \\
\text { total number }\end{array}$} \\
\hline $\begin{array}{ll}- & \text { Preceding } 3 \\
& \text { month period } \\
\end{array}$ & $\begin{array}{c}0.16(0.47) \\
16.0\end{array}$ & $\begin{array}{c}0.1(0.42) \\
20.0 \\
\end{array}$ & $<0.001$ & $\begin{array}{c}0.11(0.54) \\
22.0\end{array}$ & 0.069 \\
\hline $\begin{array}{ll}\text { - } & \text { Preceding } 6 \\
& \text { month period }\end{array}$ & $\begin{array}{c}0.24(0.59) \\
24.0\end{array}$ & $\begin{array}{c}0.15(0.51) \\
29.0\end{array}$ & $<0.001$ & $\begin{array}{c}0.18(0.74) \\
36.0\end{array}$ & 0.041 \\
\hline $\begin{array}{l}\text { - } \begin{array}{l}\text { Preceding } 12 \\
\text { month period }\end{array} \\
\end{array}$ & $\begin{array}{l}0.47(0.88) \\
\quad 46.0\end{array}$ & $\begin{array}{c}0.27(0.77) \\
53.0\end{array}$ & 0.589 & $\begin{array}{l}0.30(1.21) \\
\quad 60.0\end{array}$ & 0.001 \\
\hline \multicolumn{6}{|l|}{$\begin{array}{l}\text { Macrolide courses } \\
\text { mean (SD); total } \\
\text { number }\end{array}$} \\
\hline $\begin{array}{ll} & \text { Preceding } 3 \\
\text { month period }\end{array}$ & $\begin{array}{c}0.13(0.34) \\
13.0\end{array}$ & $\begin{array}{c}0.11(0.47) \\
22.0\end{array}$ & $<0.001$ & $\begin{array}{c}0.13(0.38) \\
26.0 \\
\end{array}$ & 0.614 \\
\hline $\begin{array}{ll} & \text { Preceding } 6 \\
& \text { month period } \\
\end{array}$ & $\begin{array}{c}0.26(0.56) ; \\
26.0\end{array}$ & $\begin{array}{c}0.18(0.65) \\
35.0\end{array}$ & $<0.001$ & $\begin{array}{c}0.19(0.60) ; \\
38.0\end{array}$ & 0.089 \\
\hline $\begin{array}{ll}- & \text { Preceding } 12 \\
& \text { month period } \\
\end{array}$ & $\begin{array}{c}0.37(0.74) ; \\
36.0 \\
\end{array}$ & $\begin{array}{c}0.32(0.95) ; \\
63.0\end{array}$ & 0.239 & $\begin{array}{c}0.31(0.93) \\
62.0\end{array}$ & 0.067 \\
\hline \multicolumn{6}{|l|}{$\begin{array}{l}\text { Fluoroquinolone } \\
\operatorname{courses}^{b} \text {, mean (SD); } \\
\text { total number }\end{array}$} \\
\hline $\begin{array}{ll}- & \text { Preceding } 3 \\
& \text { month period } \\
\end{array}$ & $\begin{array}{c}0.14(0.50) \\
14.0 \\
\end{array}$ & $\begin{array}{c}0.05(0.27) \\
10.0 \\
\end{array}$ & $<0.001$ & $\begin{array}{c}0.05(0.26) \\
10.0\end{array}$ & 0.018 \\
\hline $\begin{array}{ll}\text { - } & \text { Preceding } 6 \\
& \text { month period } \\
\end{array}$ & $\begin{array}{c}0.24(0.76) \\
24.0\end{array}$ & $\begin{array}{c}0.07(0.31) \\
14.0\end{array}$ & $<0.001$ & $\begin{array}{c}0.07(0.33) ; \\
14.0\end{array}$ & 0.005 \\
\hline $\begin{array}{ll}- & \text { Preceding } 12 \\
\text { month period }\end{array}$ & $\begin{array}{c}0.43(1.27) \\
42.0\end{array}$ & $\begin{array}{c}0.11(0.40) \\
22.0\end{array}$ & $<0.001$ & $\begin{array}{c}0.15(0.69) \\
30.0\end{array}$ & 0.011 \\
\hline
\end{tabular}

B1 medical admissions, B2 general medicine, C5 female surgery, C6 male surgery.

${ }^{\text {a }}$ Classified according to the international classification of diseases.

${ }^{\mathbf{b}}$ Numbers representing the count of the treatment courses within primary care.

Variables with $p$ values $\leq 0.25$ are displayed in bold; these $P$ values refer to comparison of cases with controls in both study phases. 
590

591

592

593

594

595

596

597

598

599

600

601

602

603

604

605

606

607

608

609

Table 3 Output of multivariate analyses (carried out in phase 1 and phase 2), regarding variables that were independently associated with MRGN bacteria.

\begin{tabular}{|c|c|c|c|c|c|c|}
\hline Model & Variable & B & SE & OR & CI $95 \%$ & P value \\
\hline \multirow[t]{8}{*}{$\mathbf{1}^{\mathrm{a}}$} & Hospitalisation period & 0.040 & 0.011 & 1.04 & $1.02-1.06$ & $<0.001$ \\
\hline & Primary diagnosis & & & & & \\
\hline & - Circulatory system & & & 1 & & \\
\hline & - Digestive system & -0.160 & 0.535 & 0.85 & $0.30-2.43$ & 0.765 \\
\hline & $\begin{array}{l}\text { - Genitourinary } \\
\text { system }\end{array}$ & 1.489 & 0.549 & 4.43 & $1.51-13.00$ & 0.007 \\
\hline & - Injury, poisoning & -0.152 & 0.624 & 0.86 & $0.25-2.92$ & 0.808 \\
\hline & - Respiratory system & 0.038 & 0.492 & 1.04 & $0.40-2.72$ & 0.983 \\
\hline & - Other & 0.162 & 0.476 & 1.18 & $0.46-2.99$ & 0.733 \\
\hline $1^{b}$ & Hospitalisation period & 0.041 & 0.011 & 1.04 & $1.02-1.07$ & $<0.001$ \\
\hline \multirow[t]{3}{*}{$1^{c}$} & Hospitalisation period & 0.040 & 0.011 & 1.04 & $1.02-1.06$ & $<0.001$ \\
\hline & $\begin{array}{l}\text { Second and third } \\
\text { generation cephalosporins }\end{array}$ & 0.177 & 0.061 & 1.19 & $1.06-1.35$ & 0.004 \\
\hline & Fluoroquinolones & 0.438 & 0.193 & 1.55 & $1.06-2.26$ & 0.023 \\
\hline
\end{tabular}

B coefficient, $\mathbf{S E}$ standard error, $\mathbf{O R}$ odds ratio.

Variables with $\mathrm{P}$ values $\leq 0.05$ are displayed in bold.

$\mathbf{a}, \mathbf{b}, \mathbf{c}$ Evaluated antibiotic courses over periods of ${ }^{\mathbf{a}} 3$ months, ${ }^{\mathbf{b}} 6$ months and ${ }^{\mathbf{c}} 12$ months within primary care prior to hospitalisation.

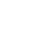




\begin{tabular}{|c|c|c|c|c|c|c|}
\hline Model & Variable & B & SE & OR & CI $95 \%$ & $\begin{array}{l}P \\
\text { value }\end{array}$ \\
\hline \multirow[t]{12}{*}{$2^{\mathrm{a}, \mathrm{b}, \mathrm{c}}$} & Hospitalisation period & 0.053 & 0.014 & 1.06 & $1.03-1.09$ & $<0.001$ \\
\hline & Primary diagnosis & & & & & \\
\hline & - Circulatory system & & & 1 & & \\
\hline & - Digestive system & 0.928 & 0.566 & 2.53 & $0.84-7.67$ & 0.101 \\
\hline & - Genitourinary system & 2.022 & 0.556 & 7.56 & $2.54-22.45$ & $<0.001$ \\
\hline & - Injury, poisoning & 0.393 & 0.635 & 1.48 & $0.43-5.14$ & 0.537 \\
\hline & - Respiratory system & 0.976 & 0.530 & 2.65 & $0.94-7.50$ & 0.066 \\
\hline & - Other & 0.828 & 0.488 & 2.29 & $0.88-5.96$ & 0.090 \\
\hline & Age & 0.037 & 0.009 & 1.04 & $1.02-1.06$ & $<0.001$ \\
\hline & Gender & & & & & \\
\hline & - Male & & & 1 & & \\
\hline & - Female & 0.813 & 0.300 & 2.26 & $1.25-4.06$ & 0.007 \\
\hline
\end{tabular}

611

612

613

614

615

616

617

618

619

620

621

622

623

624

625

626

627

628

629

B coefficient, SE standard error, OR odds ratio.

Variables with $\mathrm{P}$ values $\leq 0.05$ are displayed in bold.

$\mathbf{a}, \mathbf{b}, \mathbf{c}$ Evaluated antibiotic courses over periods of ${ }^{\mathbf{a}} 3$ months, ${ }^{\mathbf{b}} 6$ months and ${ }^{\mathbf{c}} 12$ months within primary care prior to hospitalisation.

(1)

8




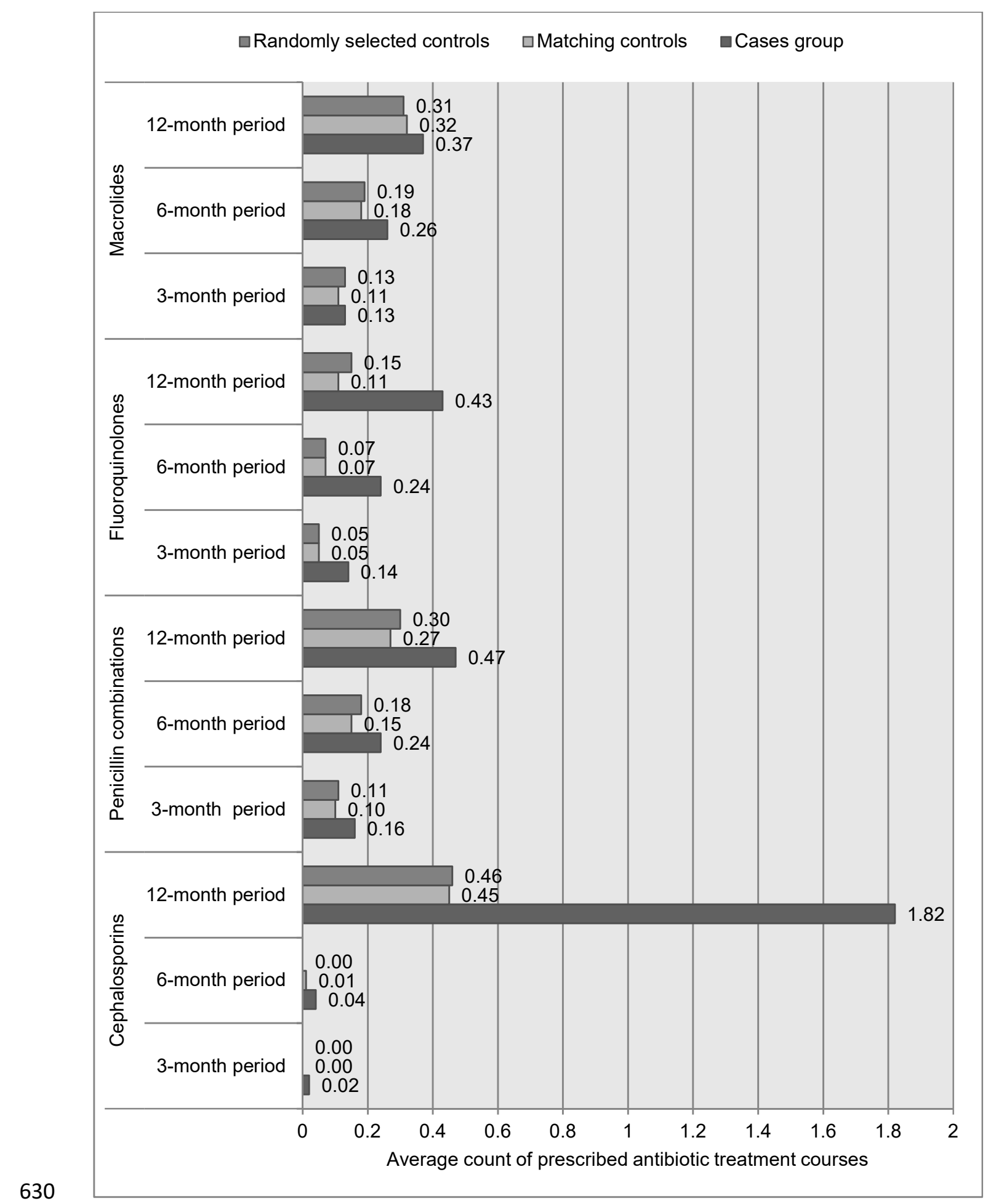

632 Fig. 1 Average number of antibiotic treatment courses (of second and third generation cephalosporins, fluoroquinolones, penicillin combinations and macrolides), which were prescribed for the cases, matched (phase 1) and randomly selected control patients (phase 2) in primary care, during the previous 3 month, 6 month and 12 month periods. 